\title{
Drug Induced Parkinsonism: An Overview
}

\author{
Bahiya Sulthana and Sujith Ovallath* \\ James Parkinson's Research Centre, Kannur Medical College, India
}

Submission: March 22, 2017; Published: May 05, 2017

*Corresponding author: Sujith Ovallath, James Parkinson's Research Centre, Kannur Medical College, India, Email: sujithok@gmail.com

\begin{abstract}
Ever since 1950s from reserpine rat model to [18F] FP-CIT PET scan, our knowledge of drug induced Parkinsonism has been constantly evolving. Trend of suspected agents changed from typical antipsychotic to more commonly used drugs like Metoclopramide and more recently to newer prokinetics like levosulpiride. Even though DIP is mostly reversible, unmasking of subclinical PD and irreversible damage by the drug leads to persistent DIP. Demonstrated risk is higher with elderly and women. Symptoms can appear from 3 months (69\%) to 12 months (20\%) of the drug intake. Most of causative agents act by blocking the dopaminergic transmission in niagrostriatal pathway. The clinical syndrome is likely to present with subacute onset with symmetrical involvement. Presence of non-motor symptoms especially hyposmia and asymmetrical involvement is suggestive of degenerative Parkinsonism. DaT scan/SPECT are the investigation available to differentiate pure DIP from other forms. Management of this condition comprises of recognition of symptoms early identifying the offending agents and prompt discontinuation of the causal agent.

This result in marked improvement in about $90 \%$ patients. Medical therapy is indicated only if the symptoms persist or are problematic. Symptomatic treatment includes anti-cholinergic drugs like benztropine and trihexifenidyl, amantidine and ECT for refractory cases. Levodopa and dopminergic agonist do not offer symptomatic improvement unless there is presence of degenerative component. In this era of polypharmacy and traditional medicine, the offender is rarely found and in clinical scenario DIP is rarely suspected leading to unnecessary use of dopaminergic agonist for a prolonged period. Whatever the trends may be, unrecognized DIP is burdensome particularly for the elderly in terms of morbidity, prolonged hospital stay, unnecessary drug intake along with its side effect and devastating economic consequences.
\end{abstract}

Keywords: Parkinsonism; Drug induced; Rigidity; Freezing

\section{Introduction}

For more than half a century, drug induced Parkinsonism (DIP) has captured the attention of the physicians and researchers alike. More and more drugs underwent extensive scrutiny and causal agents were penned down from notorious antipsychotics [1] to more innocent anti-arrhythmic agents [2]. Earlier studies kept DIP as commonest cause of secondary Parkinsonism and the second commonest cause of parkinsonism second to idiopathic Parkinson's disease [3-5]. A recent study showed not only reduction of $68.6 \%$ in the incidence of DIP over a 30-year period from 1976 to 2005 but also a relatively rare type of parkinsonism compared with other neurodegenerative types in persons aged 40 years or older [6]. This finding was attributed to substitution of typical antipsychotics by newer and safer atypical antipsychotics in psychiatric practice [6]. But due to reported safety profile, widely used atypical antipsychotics has been overlooked from suspicion of causing DIP [7]. Common drugs such as levosulpiride used in combination with proton pump inhibitors for dyspepsia causing DIP is on the rise [8]. Falling incidence can as well be true or it can be due to under recognition by the treating physician or over confidence in safety profile of certain agents. Although challenging, diagnosing DIP can help prevent unnecessary long term use of dopaminergic agents and its detrimental side effects.

This review highlights the recent trends, more on the largely overlooked drugs that can cause DIP and need for awareness among treating physicians to rethink about their prescriptions.

\section{History}

Use of chlorpromazine for psychosis and reserpine for high blood pressure triggered recognition of DIPs in early 1950s [9]. The reserpine-treated rodent model was instrumental in first demonstrating the therapeutic efficacy of levodopa by carlsson and his collegues in 1957 [10], which still remains the gold standard till to date. Reversal of reserpine induced akinesia by levodopa also demonstrated parkinsonism was related to dopamine rather than serotonin [11]. Reserpine induces an akinetic state and bradykinesia by depleting brain monoamines, which led to understanding links between monoamine depletion 
and parkinsonian symptoms [12]. Basement of treatment for Parkinsonism was laid when it was recognized that reserpine use produces parkinsonian features in human similar to idiopathic Parkinson's disease [13]. This effect was soon recapitulated in humans by Degkwitz and collegues in 1960 [14].

All the agents used to manage parkinsonism symptoms including apomorphine, pramipexole, ropinirole, pergolide, bromocriptine and cabergoline [15-20] along with muscarinic antagonists such as benztropine and trihexyphenidyl [15], MAO-B or COMT inhibitors such as selegiline, rasagiline or tolcapone $[17,21]$ and amantadine $[15,17]$ has proved their efficacy either alone or in combination in reserpine-treated rats. Later haloperidol-treated rats and models such as the classical 6-hydroxydopamine (6-OHDA) rat and 1-methyl-4-phenyl1,2,3,6-tetrahydropyridine (MPTP) mouse models later were used to extensively to study pathogenesis and various drugs [22]. DIP paved the path to understanding the pathogenesis of Parkinsonism and discovery of levodopa and other drugs useful in the treatment of Parkinsonism.

\section{Definition}

DIP can be defined as reversible development of parkinsonian syndrome in patients treated with drugs which impair dopamine function [23]. Parkinsonian syndromes includes symptom complexes such as tremor, rigidity and bradykinesia in addition to loss of postural reflexes and freezing [24]. Time for recovery from DIP may vary from days to years after offensive drugs are withdrawn [25]. Though reversible, in significant amount of individuals even after withdrawing the causal agents the symptoms persisted [26-29]. This may indicate ongoing toxicity, irreversible deficit or unmasking of underlying parkinsonism syndrome [23,25,30-31]. Symptoms after suspected drug intake appears bimodal with $69 \%$ showing symptoms after 3 months and $20 \%$ after 12 months [2]. Nevertheless, it's clear that unrecognized DIP ultimately results in significant morbidity, treatment non-compliance and disability.

\section{Epidemiology}

According the record based study done in Minnesota between 1985-2005, the average annual incidence rate of DIP over 30 years was 3.3 per 100,000 person-years overall (108 patients), 2.1 in men (33 patients), and 4.3 in women (75 patients). In the youngest age group (0-39 years), DIP was the most common type of Parkinsonism, accounting for 11 of 15 cases $(73.3 \%)$ [6]. Another survey done among elderly in brazil, prevalence of parkinsonism was found to be $7.2 \%$ and DIP was $2.7 \%$ second to $\mathrm{PD}(3.3 \%)$ [3]. Door to door survey including elderly in central Spain, DIP accounted for almost 22\% of all Parkinsonism [4]. In another study conducted in neurology and movement disorder clinic, it accounted for $4-6.8 \%$ of all parkinsonism $[7,32]$. There are only selected few studies which determines the epidemiological parameters of DIP and extrapolation of these values to other population still remains questionable.
The incidence of DIP increased with older age, and was higher in women than men at all ages; although incidence of parkinsonism is more in men [6]. The age-related decline in number and integrity of dopaminergic neurons [33], a higher use of dopamine-blocking or dopamine-depleting drugs in older subjects $[34,35]$ for mood disorders and palliative care in the elderly can be contributing reasons for the increased incidence [36]. It is proven that older individual using neuroleptics presenting with parkinsonian symptoms is five times more likely to be started on anti-parkinsons medication than a non-user [37]. Increased incidence in women can be explained by the antidopaminergic action of estrogen in extrapyramidal system [38] and also secondary factors like higher consumption of drugs with better compliance [2]. In a study by Esper and Stewart; out of 354 parkinsonism 24 were cases DIP and 19 out of which were misdiagnosed and started on dopaminergic drug while on inciting drugs [7].

\section{Causal agents}

In a 17 years surveillance conducted in regional pharmacovigilance center in France; suspected drugs involved were dopaminergic antagonist (49\%), followed by antidepressants (8\%), calcium channel blockers (5\%), peripheral dopaminergic antagonists (5\%), and $\mathrm{H} 1$ antihistamines (5\%) along with some cases with lithium, valproic acid, amiodarone, anticholinesterases, or trimetazidine [2].

A 30 year population based study, it was found that typical antipsychotic medications were the drugs most frequently associated with DIP. Among study group, 59.3\% were treated for schizophrenia and psychosis, $16.7 \%$ for severe mood disorders, $12.0 \%$ for severe dementia with agitation, $7.4 \%$ for chronic nausea, and $4.6 \%$ for other indications developed DIP [6]. Another study done in 2015, suspected drugs were mainly levosulpiride, flunarizine and olanzapine compared to typical antipsychotics.

In early 1950s neuroleptic agents was extensively used in treatment of schizophrenia, led to discovery of extrapyramidal side effects which included Parkinsonism, akathisia, acute dystonia and tardive dyskinesia and in one quarter of the patients DIP was observed [39]. Typical antipsychotics which frequently associated with DIP are chlorpromazine, prochlorperazine, perphenazine, fluphenazine, promethazine, haloperidol, pimozide and sulpiride [40]. These agents inhibit dopaminergic transmission by blocking D2 receptor, in mesocorticolimbic system treating psychosis and in niagrostriatal pathway causing EPS [41].

After the introduction of atypical antipsychotics which had relatively safer profile, the use gradually declined along with incidence of the DIP reports. But newer studies suggests approximately 50-64\% of drug induced or worsened Parkinsonism is due to drugs other than typical antipsychotics $[2,42]$. 
Atypical antipsychotics (AA) like risperidone olanzapine ziprasidone and aripiprazole have also been frequently implicated to cause DIP [40]. Since AA has partial agonist action at dopamine receptors and preference to other subtypes of receptors, hence said to be safer than its predecessor [43]. But the difference of risk doesn't hold good for higher doses [44-49] except for clozapine [46]. DIP caused by AA is severely overlooked due to misconceptions that AA is safe in terms of EPS while study suggest that $46 \%$ of DIP were contributed by AA and often missed even by neurologist [7].

Dopamine depletors such as reserpine and tetrabenazine frequently cause DIP by interfering with the vesicular storage of the monoamines [50-51]. Calcium channel blockers, flunarizine and cinnarizine were withdrawn from markets of many countries as it was frequently associated with DIP [27,43]. Now other agents like diltiazem [52] and verapamil [53] are under the scrutiny for the same.

Antiemetics like metoclopramide [28], levosulpiride [8] and clebopride [43] are another group of drug potentially notorious in causing DIP .These drugs act by blocking dopaminergic receptors like typical antipsychotics and poses more risk as these are extensively used by all practitioners. Other agents causing DIP by blocking dopaminergic transmission via various mechanism are anti-arrhythmic amiodarone [54,55], lithium [56], sodium valproate [57] and SSRIs [58,59].

\section{Idiopathic Parkinson's disease (iPD) vs Drug induced Parkinsonism}

Over the time biggest challenge encountered in DIP is to differentiate it from iPD. Any patient presenting to out-patient department with symptoms suggestive of Parkinsonism syndrome should undergo detailed history about medication taken during past year. DIP is more common in elderly individual with subacute onset of symptoms suggesting bilateral and symmetrical involvement $[5,43]$. iPD seen after 6 th decade of life tend to present as asymmetrical involvement $[5,43]$. Though asymmetry said to be predictor of iPD, there have been DIP cases reported with asymmetrical involvement $[60,61]$. In most cases of the DIP, levodopa has no effect on the patient's symptom complex in comparison to iPD.

Degenerative PD is associated with non-motor symptoms like impotence, dream enactment and disturbances of sleep, olfactory dysfunction, mood changes, cognitive decline and autonomic dysfunctions [62]. Among which hyposmias a credible predictor favoring degenerative parkinsonism over DIP [63]. In comparison to schizophrenia patients without DIP, cognitive disturbance is more common in patient with DIP [64]. iPD patients also endorsed more of "loss of facial expression" comparatively [65]. Whereas DIP patients exhibited orofacial dyskinesia and akathisia when on neuroleptics [5].

Dopamine transporter ligand scan (DaT) with good specificity and sensitivity can differentiate between a true DIP and degenerative Parkinsonism including the unmasking of subclinical PD [66]. This determines need for levodopa in DIP unmasking the subclinical PD [66]. DaT scan is abnormal in degenerative parkinsonism while normal in pure DIP. Positron emission tomography/single proton emission computerized tomography (PET/SPECT) imaging shows reduced uptake of presynaptic markers and normal uptake of dopamine receptor ligands in degenerative parkinsonism and vice versa in DIP [66]. Lately [18F] FP-CIT PET scan is under research and study shows the normal scans are associated with shorter duration to the causal agents [42]. Transcranial sonography of substantia nigra has low sensitivity and specificity in differentiating the DIP from iPD and no evidence to support its use [66].

\section{Prevention and Treatment}

Avoiding the prescription the causative drugs, substitution with safer agents and evaluating risk vs benefit of the prescription especially in high risk category like elderly and women seems to be the best approach in prevent DIP. Suspecting possibilities of DIP in individuals presenting with parkinsonian symptoms and withholding the causative agents to counter DIP. Withdrawal of offensive agent remains the management of choice, while medical therapy is indicated if the withdrawal doesn't improve the situation.

All DIP needn't be treated, only after assessing the degree of distress to patient a decision should be made. Use of anticholinergic drugs like benztropine and trihexifenidyl abated most of the symptoms caused but great caution in its use elderly as it may increase risk of delirium and amnesia [67]. But side effect profile of anti-cholinergics makes it less desirable choice. Alternative choice is Amantidine which is as effective as anticholinergic with fewer side effects making it more user friendly [68]. Levodopa can be used in DIP where drugs causes dopamine depletion like tetrabenazine, but can prove detrimental if used in dopamine receptor blocker [69]. Dopaminergic agonist and levodopa won't be acting in striatal D2 blockade, in contrary will exaggerate psychosis. Persistent DIP due to unmasking of degenerative changes in nerve ending in niagrostriatal pathway should be treated as idiopathic Parkinson's disease [25]. Refractory cases might require electroconvulsive therapy which ameliorates the Parkinsonism along with underlying condition like psychosis and schizophrenia [70-72].

\section{Conclusion}

Irrespective of incidence, possibility of DIP should be kept in mind while encountering a patient with possible Parkinsonism. In this era of polypharmacy with drug available over the counter and conventional medicines with unknown content the possibility of identifying the offending drug is a difficult task. All the medications taken by the patient during last year should be put under the scrutiny and medication other than the essential ones deemed by the treating physician should be discontinued. Strict ADR surveillance is essential for newer agents' role in DIP. Reviewing suspected patients with DIP up to a year may be required for ascertainment of the diagnosis. 


\section{Open Access Journal of Neurology \& Neurosurgery}

\section{References}

1. Weiden PJ, Mann JJ, Haas G, Mattson M, Frances A (1987) Clinical nonrecognition of neuroleptic-induced movement disorders: a cautionary study. Am J Psychiatry 144 (9): 1148-1153.

2. Bondon-Guitton E, Perez-Lloret S, Bagheri H, Brefel C, Rascol O, et al (2011) Drug induced parkinsonism: a review of 17 years' experience in a regional pharmacovigilance center in France. MovDisord 26 (12): 2226-2231.

3. Barbosa MT, Caramelli P, Maia DP, Cunningham MC, Guerra HL, et al. (2006) Parkinsonism and Parkinson's disease in the elderly: a community-based survey in Brazil (the Bambui study). Mov Disord 21(6s): 800-808.

4. Benito-Leon J, Bermejo-Pareja F, Rodriguez J, Molina JA, Gabriel R, et al. (2003) Prevalence of PD and other types of parkinsonism in three elderly populations of central Spain. Mov Disord 18(3): 267-274.

5. Sendón L, Luis J, Mena MA, de Yébenes JC (2012) Drug-induced parkinsonism in the elderly. Drugs Aging 29(2): 105-118.

6. Savica R, Grossardt BR, Bower JH, Ahlskog JE, Mielke MM, et al. (2017) Incidence and time trends of drug-induced parkinsonism: A 30-year population-based study. Mov Disord 32(2): 227-234.

7. Esper, Christine D, Stewart A (2008) Failure of recognition of druginduced parkinsonism in the elderly. Movement Disorders 23(3): 401404.

8. Mathew T, Nadimpally US, Prabhu AD, Nadig R (2017) Drug-induced Parkinsonism on the rise: Beware of levosulpiride and its combinations with proton pump inhibitors. Neurol India 65(1): 173-174.

9. Steck H (1954) Extra pyramidal and diencephalic syndrome in the course of Largactil and Serpasil treatments. Ann Med Psychol 112(25): 737-744.

10. Carlsson A, Lindqvist M, Magnusson T (1957) 3,4-Dihydroxyphenylalanine and 5-hydroxytryptophan as reserpine antagonists. Nature 180(4596): 1200.

11. Carlsson A (2001) A paradigm shift in brain research. Science 294 (5544): 1021-1024.

12. Carlsson A (1959) The occurrence, distribution and physiological role of catecholamines in the nervous system. Pharmacol Rev 11(2 Pt 2): 490-493.

13. Freyhan FA (1957) Psychomotility and parkinsonism in treatment with neuroleptic drugs. AMA Arch Neurol Psychiatry 78(5): 465-472.

14. Degkwitz R, Frowein R, Kulenkampff C, Mohs U (1960) On the effects of L-dopa in man and their modification by reserpine, chlorpromazine, iproniazid and vitamin B6. KlinWochenschr 38: 120-123.

15. Goldstein JM, Barnett A, Malick JB (1975) The evaluation of antiparkinson drugs on reserpine-induced rigidity in rats. Eur J Pharmacol 33(1): 183-188.

16. Johnson AM, Loew DM, Vigouret JM (1976) Stimulant properties of bromocriptine on central dopamine receptors in comparison to apomorphine, (+)-amphetamine and L-DOPA. Br J Pharmacol 56(1): 59-68.

17. Colpaert FC (1987) Pharmacological characteristics of tremor, rigidity and hypokinesia induced by reserpine in rat. Neuropharmacology 26(9): 1431-1440.

18. Miyagi M, Arai N, Taya F, Itoh F, Komatsu Y, et al. (1996) Effect of cabergoline, a long-acting dopamine D2 agonist, on reserpine-treated rodents. Biol Pharm Bull 19(11): 1499-1502.

19. Maj J, Rogoz Z, Skuza G, Kolodziejczyk K (1997) The behavioural effects of pramipexole, a novel dopamine receptor agonist. Eur J Pharmacol 324: 31-37.
20. Fukuzaki K, Kamenosono T, Nagata R (2000) Effects of ropinirole on various Parkinsonian models in mice, rats, and cynomolgus monkeys. PharmacolBiochemBehav 65(3): 503-508.

21. Finberg JP, Youdim MB (2002) Pharmacological properties of the antiParkinson drug rasagiline; modification of endogenous brain amines, reserpine reversal, serotonergic and dopaminergic behaviours. Neuropharmacol 43(7): 1110-1118.

22. Duty S, Jenner P (2011) Animal models of Parkinson's disease: a source of novel treatments and clues to the cause of the disease. Br J Pharmacol 164(4): 1357-1391.

23. López-Sendón J, Mena MA, de Yébenes JG (2013) Drug-induced parkinsonism. Expert Opinion on Drug Safety 12(4): 487-496.

24. Friedman JH, Trieschmann ME, Fernandez HH (2005) Drug induced parkinsonism. In: Factor S, Lang AE, Weiner WJ (Eds.) Drug induced movement disorders. ( $2^{\text {nd }}$ edn), Blackwell Futura, Newyork, USA, pp. 103-109.

25. Tinazzi M, Antonini A, Bovi T, Pasquin I, Steinmayr M, et al. (2009) Clinical and [123I]FPCIT SPET imaging follow-up in patients with druginduced parkinsonism. J Neurol 256(6): 910-915.

26. Shin HW, Kim MJ, Kim JS, Lee MC, Chung SJ (2009) Levosulpirideinduced movement disorders. MovDisord 24(15): 2249-2253.

27. Marti-Masso JF, Poza JJ (1998) Cinnarizine-induced parkinsonism: ten years later. MovDisord 13(3): 453-456.

28. Sethi KD, Patel B, Meador KJ (1989) Metoclopramide-induced parkinsonism. South Med J 82(12): 1581-1582.

29. Stephen PJ, Williamson J (1984) Drug-induced parkinsonism in the elderly. Lancet 2(8411): 1082-1083.

30. Erro R, Bhatia KP, Tinazzi M (2015) Parkinsonism following neuroleptic exposure: A double-hit hypothesis? MovDisord 30(6): 780-785.

31. Foubert-Samier A, Helmer C, Perez F, Le Goff M, Auriacombe S, et al. (2012) Past exposure to neuroleptic drugs and risk of Parkinson disease in an elderly cohort. Neurology 79(15): 1615-1621.

32. Gershanik OS (1994) Drug-induced parkinsonism in the aged. Recognition and prevention. Drugs Aging 5(2): 127-132.

33. Caligiuri MP, Lacro JP, Jeste DV (1999) Incidence and predictors of druginduced parkinsonism in older psychiatric patients treated with very low doses of neuroleptics. J ClinPsychopharmacol 19(4): 322-328.

34. Tundo A, de Filippis R, Proietti L (2015) Pharmacologic approaches to treatment resistant depression: Evidences and personal experience. World J Psychiatry 5(3): 330-341.

35. Alexopoulos GS, Streim J, Carpenter D, Docherty JP (2004) Using antipsychotic agents in older patients. J Clin Psychiatry 65(Suppl 2): 5-99.

36. Simoni-Wastila L, Wei YJ, Lucas JA, Brandt N, Moyo P, et al (2016) Mortality risk of antipsychotic dose and duration in nursing home residents with chronic or acute indications. J Am GeriatrSoc 64(5): 973980 .

37. Avorn J, Bohn RL, Mogun H, Gurwitz JH, Monane M, et al. (1995) Neuroleptic drug exposure and treatment of parkinsonism in the elderly: a case-control study. Am J Med 99(1): 48-54.

38. Session DR, Pearlstone MM, Jewelewicz R, Kelly AC (1994) Estrogens and Parkinson's disease. Med Hypotheses 42(4): 280-282.

39. Janno S, Holi M, Tuisku K, Wahlbeck K (2004) Prevalence of neurolepticinduced movement disorders in chronic schizophrenia inpatients. Am J Psychiatry 161(1): 160-163.

40. Shin HW, Chung SJ (2012) Drug-Induced Parkinsonism. Journal of Clinical Neurology 8(1): 15-21. 


\section{Open Access Journal of Neurology \& Neurosurgery}

41. Thanvi B, Treadwell S (2009) Drug induced parkinsonism: a common cause of parkinsonism in older people. Postgrad Med J 85(1004): 322 326

42. Shin HW, Kim JS, Oh M, You S, Kim YJ, et al. (2015) Clinical features of drug-induced parkinsonism based on [18F] FP-CIT positron emission tomography. Neurol Sci 36(2): 269-274.

43. Mena MA, de Yébenes JG (2006) Drug-induced parkinsonism. Expert Opinion on Drug Safety 5(6): 759-771.

44. Carlsson A (1965) The mechanism of action of neuroleptics and antidepressive drugs. Lakartidningen 62(25): 1978-1990.

45. Friedman JH (2003) A typical antipsychotics in the EPS-vulnerable patient. Psychoneuroendocrinology 28(Suppl 1): 39-51.

46. Iqbal Mm, Rahman A, Husain Z (2003) Clozapine: a clinical review of adverse effects and management. Ann Clin Psychiatry 15(1): 33-48.

47. Lieberman JA, Tollefson G, Tohen M, Green AI, Gur RE, et al. (2003) Comparative efficacy and safety of atypical and conventional antipsychotic drugs in first-episode psychosis: a randomized, doubleblind trial of olanzapine versus haloperidol. Am J Psychiatry 160(8): 1396-1404.

48. Sakata MA, Ohtani H, Sawada Y (2005) Pharmacokineticpharmacodynamic analysis of antipsychotics-induced extrapyramidal symptoms based on receptor occupancy theory incorporating endogenous dopamine release. Drug Metab Pharmacokinet 20(3): 187-199.

49. Ritchie CW, Chiu E, Harrigan S (2003) The impact upon extra-pyramidal side effects, clinical ymptoms and quality of life of a switch from conventional to atypical antipsychotics (risperidone or olanzapine) in elderly patients with schizophrenia. Int J Geriatr Psychiatry 18(5): 432-440.

50. Sommet A, Azais-Vuillemin C, Bagheri H, Rascol O, Montastruc JL (2005) Trimetazidine: a new cause for drug-induced parkinsonism? Mov Disord 20(8): 1080-1081.

51. Giladi N, Melamed E (1999) Levodopa therapy can ameliorate tetrabenazine-induced parkinsonism. Mov Disord 14(1): 158-159.

52. Remblier C, Kassir A, Richard D, Perault MC, Guibert S (2001) Parkinson syndrome from diltiazem. Therapie 56(1): 57-59.

53. Padrell MD, Navarro M, Faura CC, Horga JF (1995) Verapamil-induced parkinsonism. Am J Med 99(4): 436.

54. Dotti MT, Federico A (1995) Amiodarone-induced parkinsonism: case report and pathogenetic discussion. Mov Disord 10(2): 233-234.

55. Werner EG, Olanow CW (1989) Parkinsonism and amiodarone therapy. Ann Neurol 25(6): 630-632.

56. Dallocchio C, Mazzarello P (2002) A case of Parkinsonism due to lithium intoxication: treatment with pramipexole. J Clin Neurosci 9(3): 310-311.

57. Ricard C, Martin K, Tournier M, Begaud B, Verdoux H (2005) A case of Parkinsonian syndrome, cognitive impairment and hyperammonemia

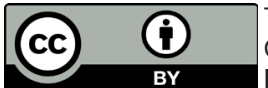

his work is licensed under Creative Commons Attribution 4.0 Licens DOI: 10.19080/OAJNN.2017.03.555620 induced by divalproate sodium prescribed for bipolar disorder. Encephale 31(1 Pt 1): 98-101.

58. Arai M (2003) Parkinsonism associated with a serotonin and noradrenaline reuptake inhibitor, milnacipran. J Neurol Neurosurg Psychiatry 74(1): 137-138.

59. Gony M, Lapeyre-Mestre M, Montastruc JL (2003) Risk of serious extrapyramidal symptoms in patients with Parkinson's disease receiving antidepressant drugs: a pharmacoepidemiologic study comparing serotonin reuptake inhibitors and other antidepressant drugs. Clin Neuropharmacol 26(3): 142-145.

60. Hardie RJ, Lees AJ (1988) Neuroleptic-induced Parkinson's syndrome: clinical features and results of treatment with levodopa. J Neurol Neurosurg Psychiatry 51(6): 850-844.

61. Sethi KD, Zamrini EY (1990) Asymmetry in clinical features of druginduced parkinsonism. J Neuropsychiatry Clin Neurosci 2(1): 64-66.

62. Erro R, Picillo M, Vitale C, Amboni M, Moccia M, et al. (2013) Nonmotor symptoms in early Parkinson's disease: a 2-year follow-up study on previously untreated patients. J Neurol Neurosurg Psychiatry 84(1): 14-17.

63. Brigo F, Erro R, Marangi A, Bhatia K, Tinazzi M (2014) Differentiating drug-induced parkinsonism from Parkinson's disease: an update on non-motor symptoms and investigations. Parkinsonism \& related disorders 20(8): 808-814.

64. Kim JH, Kim SY, Byun HJ (2008) Subjective cognitive dysfunction associated with drug-induced Parkinsonism in schizophrenia. Park Relat Disord 14(3): 239-242.

65. Morley, James F (2014) Motor and non-motor features of Parkinson's disease that predict persistent drug-induced Parkinsonism. Parkinsonism Relat Disord 20(7): 738-742.

66. Kagi G, Bhatia KP, Tolosa E (2010) The role of DAT-SPECT in movement disorders. J Neurol Neurosurg Psychiatry 81(1): 5-12.

67. Saltz BL, Woerner MG, Robinson DG, Kane JM (2000) Side effects of antipsychotic drugs. Avoiding and minimizing their impact in elderly patients. Postgrad Med 107(2): 169-178.

68. Fahn WE, Lake CR (1976) Amantadine versus trihexyphenidyl in the treatment of neuroleptic-induced parkinsonism. Am J Psychiatry 133(8): 940-943.

69. Jankovic J, Beach J (1997) Long-term effects of tetrabenazine in hyperkinetic movement disorders. Neurology 48(2): 358-362.

70. Hanin B, Lerner Y, Srour N (1995) An unusual effect of ECT on druginduced parkinsonism and tardive dystonia. ConvulsTher 11(4): 271274 .

71. Goswami U, Dutta S, Kuruvilla K (1989) Electroconvulsive therapy in neuroleptic-induced parkinsonism. Biol Psychiatry 26(3): 234-248.

72. Baez MA, Avery J (2011) Improvement in drug-induced parkinsonism with electroconvulsive therapy. Am J Geriatr Pharmacother 9(3): 190193.

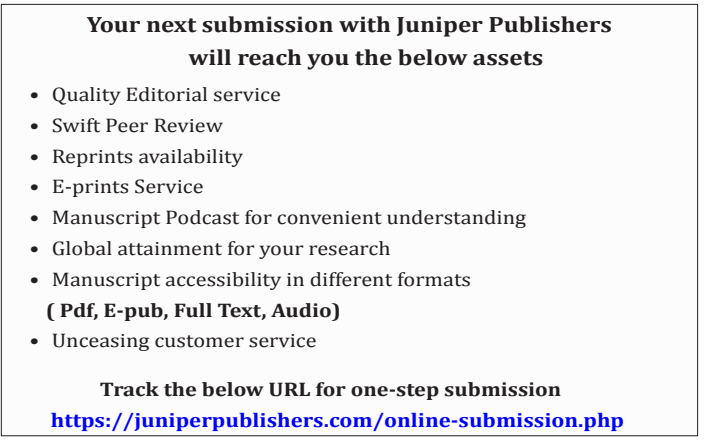

